An important next step would be to evaluate the natural history of children who successfully underwent surgical treatment of OSA. Many studies suggest that a significant number of children have incomplete resolution of OSA after surgery, but we do not know how many children worsen over time.

In summary, this is an important first study but much needs to be done before we can decide whether watchful waiting is a valid long-term management plan for children with mild OSA.

Competing interests: None.

Thorax 2010;65:4-5. doi:10.1136/thx.2009.123141

\section{REFERENCES}

1. Redline S, Tishler PV, Schluchter M, et al. Risk factors for sleep-disordered breathing in children Associations with obesity, race, and respiratory problems. Am J Respir Crit Care Med 1999;159:1527-32

2. Lumeng JC, Chervin RD. Epidemiology of pediatric obstructive sleep apnea. Proc Am Thorac Soc 2008;5:242-52.

3. Uliel S, Tauman R, Greenfeld M, et al. Normal polysomnographic respiratory values in children and adolescents. Chest 2004;125:872-8.

4. Traeger N, Schultz B, Pollock AN, et al. Polysomnographic values in children 2-9 years old: additional data and review of the literature. Pediatr Pulmonol 2005; 40:22-30.

5. Witmans MB, Keens TG, Davidson Ward SL, et al. Obstructive hypopneas in children and adolescents: normal values. Am J Respir Crit Care Med 2003;168:1540.
6. Li AM, Au CT, Ng SK, et al. Natural history and predictors for progression of mild childhood obstructive sleep apnoea. Thorax 2009;65:27-31.

7. Erickson BK, Larson DR, St Sauver JL, et al. Changes in incidence and indications of tonsillectomy and adenotonsillectomy, 1970-2005. Otolaryngol Head Neck Surg 2009;140:894-901.

8. Chervin RD, Ruzicka DL, Giordani BJ, et al. Sleepdisordered breathing, behavior, and cognition in children before and after adenotonsillectomy. Pediatrics 2006;117:e769-78.

9. O'Brien LM, Mervis CB, Holbrook CR, et al. Neurobehavioral implications of habitual snoring in children. Pediatrics 2004;114:44-9.

10. Amin RS, Carroll JL, Jeffries JL, et al. Twenty-four-hour ambulatory blood pressure in children with sleep-disordered breathing. Am J Respir Crit Care Med 2004;169:950-6.

11. Moyer-Mileur LJ, Nielson DW, Pfeffer KD, et al. Eliminating sleep-associated hypoxemia improves growth in infants with bronchopulmonary dysplasia. Pediatrics 1996:98:779-83.

\title{
Seldinger chest drain insertion: simpler but not necessarily safer
}

\section{Nick A Maskell, ${ }^{1}$ Andrew Medford, ${ }^{1}$ Fergus V Gleeson ${ }^{2}$}

A symptomatic pleural effusion is a common cause of presentation to medical admission units across the UK. Traditionally, large-bore Argyle-type drains were inserted but, over the past decade, there has been a move to inserting small-bore 10-12 French gauge drains using the Seldinger technique. ${ }^{1}$ In a recently published report, over 20000 units of one Seldinger-type drain were sold in the UK in 2004. ${ }^{2}$ The reasons for this include a perceived reduction in patient discomfort and invasiveness, and the apparent ease and speed of insertion of the smaller drains. This change in practice has occurred alongside new methods of training junior doctors, with Modernising Medical Careers and the European Working Time Directive leading to a reduction in their total work hours and a move to shift work patterns. This has inevitably led to reduced trainee experience on the "shop floor".

Surveys on chest drain insertion have shown that, even among experienced respiratory physicians and thoracic surgeons, overpenetration of the trocar and visceral injuries using Argyle-type chest drains occur. ${ }^{4}$ This led to suggestions to

\footnotetext{
${ }^{1}$ North Bristol Lung Centre, Southmead Hospital, Bristol, UK; ${ }^{2}$ Department of Radiology, Churchill Hospital, Oxford, UK

Correspondence to: Dr N A Maskell, North Bristol Lung Centre, Southmead Hospital, Bristol BS10 5NB, UK; nick. maskell@bristol.ac.uk
}

improve safety and the removal of trocars from some Argyle drain packs.

It has been assumed that the recent change in chest drain insertion to the use of smaller bore chest drains inserted using the Seldinger technique is safer, but there is at present no evidence to support this assumption. Unfortunately, they may cause the same array of problems in inexperienced hands and may potentially expose the patient to additional risks from the use of the sharp long dilator in the small-bore catheter packs and, as the blunt dissection technique is not used, the intercostal artery may be more vulnerable using this approach. Complications of small-bore chest tubes include:

- Puncture of the intercostal artery.

- Over-introduction of the dilator into the chest cavity causing organ perforation.

- Hospital-acquired pleural infection using a non-aseptic technique.

- Inadequate "stay" suture allowing the chest tube to fall out.

- Tube blockage, which may be more common than with larger bore Argyle drains.

The recent National Patient Safety Agency (NPSA) alert reported 12 deaths and 15 cases of serious harm related to chest drain insertion between January 2005 and March 2008. Common factors related to the incidents included the lack of experience of the operator, an inadequate level of supervision, failure to follow the manufacturer's instructions, choice of a suboptimal insertion site and poor patient positioning, suboptimal imaging and a lack of familiarity with published guidelines ${ }^{5}$ on chest drain insertion. Deaths were secondary to puncture of the heart, lungs and liver (fig 1). Severe harm occurred due to drain insertion on the wrong side, damage to vessels, the trachea and the liver. Moderate harm in most cases related to poor management after the drain had been inserted. The Medicines and Healthcare Regulatory Authority has had nine adverse incidents reported since 2003, all but one related to the use of the Seldinger technique for chest drain insertion. These reported incidents are likely to be a significant underestimate of the actual number that have occurred across the UK during this period. An abstract presented at the 2008 British Thoracic Society winter meeting reported $65 \%$ of trusts had encountered

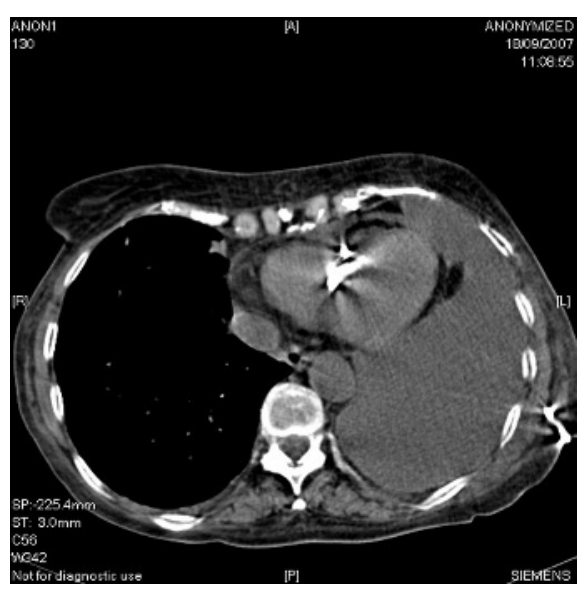

Figure 1 Small-bore chest drain misplaced in left ventricle. 
major complications with chest drain insertion over the past 5 years. ${ }^{6}$

What lessons can we learn from the NPSA report and how can we improve patient safety? It is important to understand that the reasons for the complications leading to the report are multifactorial and that a variety of solutions may be required, but there are a number of common themes that are universally applicable.

The most important of these is adequate education and training. Teaching on the risks associated with and the indications for drain insertion needs to be improved at undergraduate and postgraduate level. A decision on which doctors and specialist services are authorised to insert chest drains is needed for each Trust. Reducing the numbers of doctors who insert chest drains should increase the experience of those authorised to do so and will decrease the numbers requiring training, thus alleviating some of the pressure on training. For junior doctors, local training and assessment of trainees via log books and direct observation of procedural skills is required. There should be a chest drain/ pleural lead for each Trust who should be allowed time to teach trainees in the clinical skills laboratory using suitable models. He/she should ensure that the correct technique is being used before signing them off. National guidance is needed so that, once trained and approved by the Trust lead, a certificate can be issued for the trainee's portfolio which would remain valid when rotating between NHS trusts. In addition, webbased resources such as the British Thoracic Society pleural disease guidelines and British Medical Journal learning modules can be used to supplement training.

Second, there should be a general move to performing these procedures as an urgent planned procedure rather than as an out-of-hours emergency. This would help ensure the correct skill mix is available. If a patient is symptomatic because of a large pleural effusion at night, it would be safer to remove 11.51 with a Venflon, allowing the Trustapproved team to intervene with appropriate work-up for undiagnosed pleural effusions such as a CT scan and either chest tube insertion or referral for thoracoscopy the following day. A move away from chest tube insertion being a generic medical skill is to be encouraged, with a move to a safer service provided by fewer teams and individuals, although this change will inevitably produce alterations in working practice and staffing. Chest drain insertion outside the emergency, surgery, ITU and radiology departments is likely to be largely performed by chest physicians and their teams in the future. Larger Trusts should be encouraged to run a specialist Pleural Service so that patients are reviewed earlier by respiratory doctors with a special interest in pleural diseases, able to provide additional methods of investigation such as local anaesthetic thoracoscopy.

Ultrasound guidance has been shown to detect fluid more accurately than by chest radiography, to decrease the incidence of failed aspirations and the incidence of complications, and to be significantly better than clinical examination in choosing a site for safe aspiration or drain insertion. ${ }^{78}$ In fact, the National Institute for Health and Clinical Excellence (NICE) Interventional Procedures Programme reported in June 2006 that a formal review for the need for ultrasound pleural effusion drainage was outside its remit "because the procedure is considered standard clinical practice with risks and benefits that are sufficiently wellknown". At present most Trusts appear to rely on their radiology department to mark safe insertion sites. However, as more trainees and chest physicians are trained in thoracic ultrasound and obtain level 1 thoracic ultrasound competency ${ }^{9}$ and Trusts invest in ward-based ultrasound machines, this is likely to change. However, a note of warning needs to be sounded about the use of ultrasound in inexperienced hands. There may be a temptation with the aid of ultrasound to forget the golden rule of drain insertion over the rib, and to attempt drain insertion into small posteriorly or technically difficult positioned pleural collections which may lead to an increase in the incidence of complications. To assist trainees and respiratory physicians to acquire level 1 competency in thoracic ultrasound, more national courses are required across the UK. The British Thoracic Society education committee will also need to consider if level 1 thoracic ultrasound competency is included in the core minimum skill set for respiratory $\mathrm{SpRs}$ prior to completing their certificate of completion of specialist training.

There is also a role for the manufacturers to produce safer kits which are fit for purpose, perhaps with more graduated dilators and distance markers along them enabling only $1-2 \mathrm{~cm}$ of the dilator to be inserted into the chest cavity, allowing only dilation of the subcutaneous tissues and chest wall. Some manufacturers have already engaged in this process.

Although the focus of this article and the NPSA report is on drain insertion for pleural effusion, the majority of comments are applicable to chest drain insertion for pneumothorax. Adequate supervision, training and experience alongside the knowledge of when a drain is required are as applicable to the treatment of pneumothorax as effusion. The uncommon but potentially life-threatening emergency of a tension pneumothorax requires all doctors to be trained to identify and provide immediate treatment before referring the patient on if they are not adequately trained to insert a chest drain.

\section{Competing interests: None.}

Provenance and peer review: Not commissioned; externally peer reviewed.

Thorax 2010;65:5-6. doi:10.1136/thx.2009.117200

\section{REFERENCES}

1. Lee YC, Baumann MH, Maskell NA, et al. Pleurodesis practice for malignant pleural effusions in five Englishspeaking countries: survey of pulmonologists. Chest 2003;124:2229-38.

2. Horsley A, Jones L, White J, et al. Efficacy and complications of small-bore, wire-guided chest drains. Chest 2006;130:1857-63.

3. Bristol JB, Harvey JE. Safer insertion of pleural drains BMJ 1983;286:348-9.

4. Firmin RK, Tolhurst-Cleaver C. Safe intrapleural drainage. Anaesthesia 1980;35:79-80.

5. Laws D, Neville E, Duffy J. BTS guidelines for the insertion of a chest drain. Thorax 2003:58/Suppl 2):ii53-9.

6. Harris A, Turkington PM, O'Driscoll BR. Survey of major complications of intercostal chest drain insertion in the UK. Thorax 2008;63(Suppl Vii):A86.

7. O'Moore PV, Mueller PR, Simeone JF, et al. Sonographic guidance in diagnostic and therapeutic interventions in the pleural space. AJR Am J Roentgenol 1987;149:1-5

8. Diacon AH, Brutsche MH, Soler M. Accuracy of pleural puncture sites. A prospective comparison of clinical examination with ultrasound. Chest 2003;123:436-41.

9. Royal College of Radiologists. Ultrasound training recommendations for medical and surgical specialties. London: Royal College of Radiologists. http://www.rcr. ac.uk. 